\title{
Analyzing sediment dissolved oxygen based on microprofile modeling
}

\author{
Chao Wang $\cdot$ Baoqing Shan $\cdot$ Hong Zhang $\cdot$ Nan Rong
}

Received: 8 January 2014 / Accepted: 2 April 2014 / Published online: 26 April 2014

(C) Springer-Verlag Berlin Heidelberg 2014

\begin{abstract}
Sediment plays a key role in controlling the oxygen demand of aquatic systems. The reaction rate, penetration depth, and flux across the sediment-water interface (SWI) are important factors in sediment oxygen consumption. However, there were few methods to collect these data until recently. In this study, methods were developed to simulate the oxygen microprofile and calculate the sediment oxygen consumption rate, oxygen penetration depth, and oxygen flux across the SWI. We constructed a sediment oxygen measuring system using an oxygen microelectrode and a control device. The simulation equations were derived from both zero and first-order kinetic models, while the penetration depth and the oxygen flux were calculated from the simulation results. The method was tested on four prepared sediment samples. Decreases in dissolved oxygen in surface sediment were clearly detected by the microelectrode. The modeled data were a good fit for the observed data $\left(R^{2}>0.95\right)$, and zero-order kinetics were more suitable than first-order kinetics. The values for penetration depth (1.3-3.9 mm) and oxygen fluxes (0.061$0.114 \mathrm{mg} / \mathrm{cm}^{2} /$ day) calculated by our methods are comparable with those from other studies.
\end{abstract}

Keywords Dissolved oxygen · Sediment · Microprofile · Flux $\cdot$ Penetration depth $\cdot$ Microelectrode

Responsible editor: Philippe Garrigues

C. Wang $\cdot$ B. Shan $(\triangle) \cdot$ H. Zhang $\cdot$ N. Rong

State Key Laboratory on Environmental Aquatic Chemistry,

Research Center for Eco-Environmental Sciences, Chinese Academy

of Sciences, Beijing 100085, China

e-mail: cwrcees@163.com

C. Wang

University of Chinese Academy of Sciences, Beijing 100049, China

\section{Introduction}

Dissolved oxygen (DO) is the most important parameter in water. The proportion of oxygen in air that dissolves in water is about $35 \%$; its solubility is governed by physical and biological processes (Wetzel 2001). This double-bonded, two-atom molecule is essential to the metabolism of all aerobic aquatic organisms. Reduced oxygen levels have been shown to cause lethal and sublethal effects in various organisms, especially fish (Alabaster and Lloyd 1982). Moreover, oxygen controls the cycling of many elements in aquatic systems, such as the degradation of organic matter in sediment (Holmer 1999), the accumulation of ammonia in lake hypolimnion (Beutel 2001), and the release and uptake of cobalt, manganese, iron and phosphate (Sundby et al. 1986; Torres et al. 2013).

The issue of oxygen depletion in aquatic environments has aroused much attention worldwide. It is well known that sediment plays a key role in the oxygen demand of aquatic systems and there have already been many studies on sediment oxygen consumption (Zahraeifard and Deng 2012; Martin et al. 2013). Several factors, including the oxygen reaction rate, the depth in the sediment to which oxygen penetrates, and the oxygen flux at the sediment-water interface (SWI), have been studied repeatedly. These studies have shown that the oxygen consumption rate in the sediment is related to organic matter and oxygen concentration (Cai and Sayles 1996) and, in most cases, zero- or first-order reaction kinetics apply (Wang 1981). For first-order kinetics, there is a linear relationship between the reaction rate and the oxygen or organic matter content, while for zero-order kinetics, the reaction rate is independent of both of them. Some studies have shown that dividing the organic matter into two groups, rapid reaction and slow reaction, can improve the accuracy of the oxygen reaction rate calculation (Brady and Testa 2013). Besides organic matter, reduced substances, such as Fe and 
$\mathrm{Mn}$, are incorporated into the sediment oxygen reaction kinetics so that the reaction process can be modeled more precisely (Cai et al. 2010). Based on the reaction kinetics, the factors affecting sediment oxygen consumption can be identified quantificationally, and rates of oxygen consumption can be predicted.

The depth to which oxygen penetrates in the sediment is significant to transformations of many elements. The bottom of the oxic zone in surface sediment is an important redox boundary that is regulated by organic carbon degradation and oxygen transport. The oxygen penetration depth defines the thickness of the oxic zone and is therefore a significant parameter in the sediment. It plays a key role in fluxes of methane $\left(\mathrm{CH}_{4}\right)$, hydrogen sulfide $\left(\mathrm{H}_{2} \mathrm{~S}\right)$, and other redox substances in sediment (Sweerts et al. 1991). The degree of nitrification is also highly dependent on the oxygen penetration (Henriksen 1980). Generally, the oxygen penetration depth is very limited, ranging from tens of microns to several millimeters. In Chesapeake Bay sediment, the oxygen penetration depth was less than $1 \mathrm{~mm}$ (Kemp et al. 1990), while in an aquatic sediment with burrows and roots, all the oxygen was consumed in the top 1-5 mm (Meysman et al. 2010). Examination of the oxygen profile of an incubated sediment showed that the maximum oxygen penetration was no more than $8 \mathrm{~mm}$ (Louati et al. 2013). Because of the small scale involved, it is not easy to detect oxygen penetration in the sediment, which prevents this measurement being widely used in studies of dissolved oxygen in sediment.

The oxygen flux across the SWI, or sediment oxygen demand (SOD), is also important for aquatic systems because it directly determines the DO content of the overlying water. SOD accounted for $42 \%$ of the overall oxygen depletion in the hypolimnion of Lake Erie (Di Toro and Connolly 1980) and may be responsible for about $50 \%$ of the total oxygen depletion in some rivers (Hanes and Irvine 1966). The term SOD includes oxygen demand from two separate processes: biological respiration of all living organisms and chemical oxidation of reduced substances (Wang 1980). It can be measured by many methods, including batch, continuous flow, manometer, and electrolyte and dehydrogenase activity; these methods have been reviewed in detail by Bowman and Delfino (1980). However, these methods are timeconsuming or difficult to apply in field research. Previous studies have used oxygen microprofiling to calculate the oxygen flux. Based on the oxygen profile, oxygen fluxes across the SWI were estimated to be in the range 6.07$14.9 \mathrm{mmol} \mathrm{m}^{-2}$ day $^{-1}$ (Xu et al. 2009). The differences between microprofiles from both sides of the SWI have also been reviewed by Bryant et al. (2010). On the whole, microprofiling is a fast in situ method for analyzing SOD.

In the past, DO measurements were limited to the water column because no adequate methods were available for its detection in sediments. Measurements of sediment oxygen by extracting pore water have been reported by several authors (Brafield 1964; Hargrad 1972), but it is not easy to obtain reliable results in this way. However, the development of microelectrodes means that DO profiles in sediment can be detected. Revsbech et al. (1983) measured oxygen profiles within the microbial mat of lake sediment using a potentiometric microelectrode. Jorgensen and Revsbech (1985) found that the roughness of the sediment surface has an effect on the oxygen uptake process by recording the oxygen profile with a polarographic microelectrode. In 1995, Brendel and Luther (1995) developed the gold amalgam voltammetric microelectrode and provided a new way to analyze redox processes in the sediment. This kind of moderately sized (about $200 \mu \mathrm{m}$ ) high-strength microelectrode is optimal for fresh water sediment.

Although the DO microprofile has been used to detect the penetration depth (Xu et al. 2009) and calculate oxygen flux (Sweerts et al. 1991), there has been little discussion about how the sediment DO microprofile should be analyzed. In this study, we constructed a sediment oxygen measuring system, which was composed of a gold amalgam microelectrode and a control device. Using this system, the DO microprofiles of four prepared sediments were measured. The oxygen reaction rate, penetration depth, and flux across the SWI were analyzed from the microprofiles. The aim of this study was to provide methods to analyze DO microprofiles from modeling.

\section{Materials and methods}

\section{Oxygen microelectrode preparation}

In this section, we briefly describe the method for making a gold amalgam microelectrode; however, a more detailed explanation has been provided by Brendel and Luther (1995). We used aluminosilicate glass tubes with a 3-mm inner diameter and a 4-mm outer diameter. The middle of the glass tube was heated, and the tip was stretched until its diameter was less than $0.4 \mathrm{~mm}$. Meanwhile, we connected a 5-cm-long gold wire (100- $\mu \mathrm{m}$ diameter) to a $10-\mathrm{cm}$ long silver wire $(0.5-\mathrm{mm}$ diameter) using conductive silver epoxy. The gold wire was inserted into the tip of the glass capillary and then sealed by the epoxy. We injected the epoxy into the larger diameter of the glass tube using a syringe and allowed the epoxy to drain slowly through the smaller diameter of the glass tip. The epoxy was an effective sealant that made the electrode more waterproof (Luther et al. 2008). Once the epoxy had solidified, the end of the silver wire was ready to be used as the electrical contact of the gold electrode.

We polished the tip of the electrode using an EG-44 micropolisher (Narishige) and then washed it in an ultrasonic cleaner for $40 \mathrm{~s}$. After the final polishing, the electrode was plated with mercury (Hg) by reducing $\mathrm{Hg}$ (II) from a mercury 
nitrate $\left(0.1 \mathrm{M} \mathrm{Hg}\left(\mathrm{NO}_{3}\right)_{2}\right)$ electrolyte at a potential of $-0.10 \mathrm{~V}$ versus a solid-state silver/silver chloride $(\mathrm{Ag} / \mathrm{AgCl})$ electrode for $3 \mathrm{~min}$. A mercury layer about $40-\mu \mathrm{m}$ thick was visible on the gold disk when examined under an optical microscope. The gold/mercury $(\mathrm{Au} / \mathrm{Hg})$ amalgam interface was conditioned using a $-9 \mathrm{~V}$ polarization for $90 \mathrm{~s}$ in a $1 \mathrm{~N} \mathrm{NaOH}$ solution. Dissolved oxygen was calibrated using the Winkler titration method, which was fully described by Brendel and Luther (1995).

Measure and control system

The DO measurement instrument was based on the CHI 660 electrochemical analyzer and a standard three-electrode system was adopted: The mercury-gold $(\mathrm{Hg}-\mathrm{Au})$ microelectrode was the working electrode, the Pt wire was the counter electrode, and the solid $\mathrm{Ag} / \mathrm{AgCl}$ electrode was the reference electrode. To make a solid $\mathrm{Ag} / \mathrm{AgCl}$ electrode, we placed the silver $(\mathrm{Ag})$ wire into a chloride solution and polarized it for $20 \mathrm{~s}$ using a 9-V battery ( $\mathrm{Ag}$ wire on the+terminal and platinum $(\mathrm{Pt})$ wire on the terminal) so that a coating of silver chloride $(\mathrm{AgCl})$ would form on the Ag wire (Luther et al. 2008).

During sample measuring, the Pt electrode and the solid $\mathrm{Ag} / \mathrm{AgCl}$ electrode were first put into the overlying water, and the $\mathrm{Hg}-\mathrm{Au}$ microelectrode moved downward to the sediment controlled by a micromanipulator (Fig. 1). The downward movement of the microelectrode tip was adjusted using the

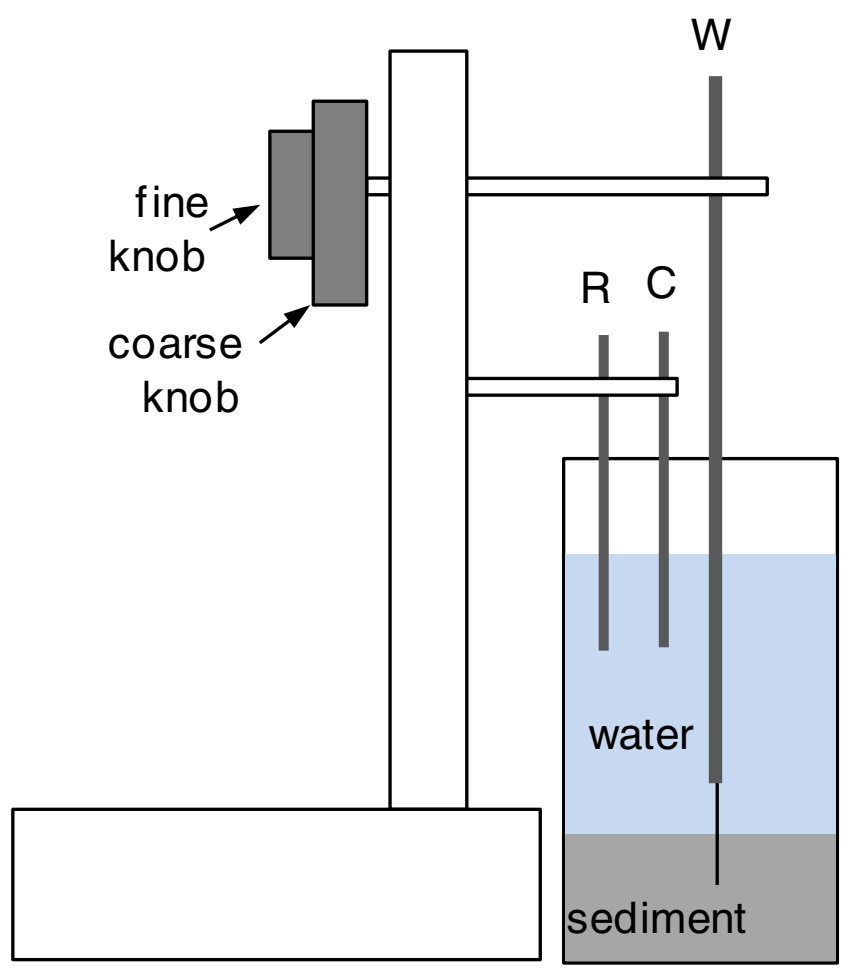

Fig. 1 Schematic of measuring and controlling system. $R$ is reference electrode, $C$ is counter electrode, $W$ is working electrode. Coarse knob and fine knob are used to adjust the altitude of working electrode coarse and fine rotary knobs of a micromanipulator, which could control downward movement of the electrode tip at a minimal step of $0.01 \mathrm{~mm}$.

We used square wave voltammetry to measure DO at a single potential scan from -0.10 to $-1.75 \mathrm{~V}$ vs $\mathrm{Ag} / \mathrm{AgCl}$. According to Luther et al. (2008), a higher scanning frequency usually produces a higher current signal, and a lower scanning frequency may produce a better shape for the current signal. A scanning rate of $25 \mathrm{~Hz}$ was chosen for balance, with a square wave amplitude of $25 \mathrm{mV}$ and a step increase of $4 \mathrm{mV}$. It took $20 \mathrm{~s}$ to scan the full potential range for each measurement. We scanned three times at each depth and took the mean value as the final result.

Method for analyzing the oxygen profile

\section{Simulation of vertical DO distribution}

The DO microprofile was simulated under steady-state conditions. To achieve steady state, (1) the oxygen at the interface should remain constant for a sufficiently long time interval so that all the oxygen that diffuses across the interface is consumed in the oxic zone and (2) the depth of the oxidized zone should be static and should not change with time (Bouldin 1968). Under steady-state conditions and negligible advection, the oxygen profile in the pore water of sediment results from a balance between diffusion and reaction (Cai and Sayles 1996) such that:

$\frac{\mathrm{d}}{\mathrm{d} z}\left(\varphi D_{\mathrm{s}} \frac{\mathrm{d} c}{\mathrm{~d} z}\right)-R_{\mathrm{O}_{2}}=0$

where $z$ is the sediment depth, $D_{\mathrm{s}}$ is the diffusion coefficient in the sediment pore water, $c$ is the $\mathrm{DO}$ concentration, $R_{\mathrm{O} 2}$ is the oxygen consumption rate, and $\varphi$ is the porosity. The rate term, $R_{\mathrm{O} 2}$, is most often expressed by first- or zero-order kinetics. We solved the equation for both situations.

For first-order kinetics, Eq. (1) becomes

$\varphi D_{\mathrm{s}} \frac{\mathrm{d}^{2} c}{\mathrm{~d} z^{2}}=\mathrm{k}_{1} c$

where $\mathrm{k}_{1}$ is the first-order reaction kinetics constant. The general solution of Eq. (2) is

$c=c_{1} \mathrm{e}^{-\mathrm{z} \sqrt{\mathrm{K}}}+c_{2} \mathrm{e}^{-\mathrm{z} \sqrt{\mathrm{K}}}$

where $c_{1}$ and $c_{2}$ are constants and $K=k_{1} /\left(\varphi D_{\mathrm{s}}\right)$. The boundary conditions can be calculated as

$c(z=0)=c_{0}$ and $(z=\infty)=0$ 
where $c_{0}$ is the oxygen concentration in the SWI. To satisfy the boundary condition (4), $c_{1}=0$ and $c_{2}=c_{0}$, which means that the solution of Eq. (2) is

$c=c_{0} \mathrm{e}^{-\mathrm{z} \sqrt{\mathrm{K}}}$

For zero-order kinetics, Eq. (1) becomes

$\varphi D_{\mathrm{s}} \frac{\mathrm{d}^{2} c}{\mathrm{~d} z^{2}}=k_{0}$

where $\mathrm{k}_{0}$ is the zero-order reaction kinetics constant. The general solution of Eq. (6) is

$c=\frac{1}{2} K z^{2}+c_{1} z+c_{2}$

where $K=k_{0} /\left(\varphi D_{\mathrm{s}}\right), c_{1}$, and $c_{2}$ are constants. Considering that the oxygen profile is monotonically decreasing and the minimal value is zero, the boundary conditions can be expressed as

$c(z=0) c_{0}$ and $c\left(\frac{\mathrm{d} c}{\mathrm{~d} z}=0\right)=0$

Under these conditions, $c_{1}= \pm \sqrt{2 c_{0} \mathrm{~K}}$ and $c_{2}=c_{0}$. As downward is positive, $c_{1}$ is assigned a negative value. To conclude the calculations, the solution for Eq. (6) is calculated as follows:

$c=\frac{1}{2} K z^{2}-\sqrt{2 c_{0} K} \times z+c_{0}$

The measured DO microprofile was simulated using Eqs. (5) and (9) in Origin 8 using nonlinear fitting tools. The simulated $\mathrm{K}$ value was assumed to be the oxygen reaction rate constant and $c_{0}$ was assumed as the oxygen concentration in the SWI. The adjusted $R^{2}$ was selected to evaluate the model fitting results.

\section{Calculation of oxygen penetration depth in sediment}

To calculate the oxygen penetration depth $\delta$, we defined the anoxic condition as the DO concentration $c$ less than a critical value $c_{\mathrm{h}}$ (Fig. 2). In this way, the penetration depth can be solved by giving $c$ a value equal to $c_{\mathrm{h}}$ in Eqs. (5) or (9). For first-order reaction kinetics, we substituted $c=c_{\mathrm{h}}$ into Eq. (5), giving a solution of

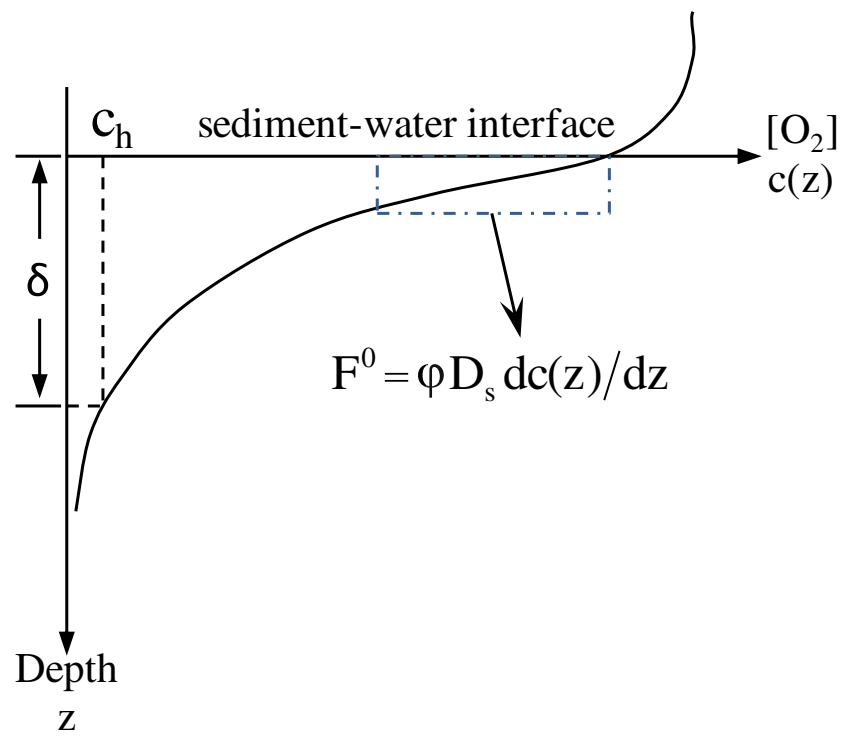

Fig. 2 Calculation of penetration depth and oxygen flux through DO microprofile. $\delta$ the penetration depth, $c_{h}$ the threshold to calculate the oxygen penetration depth, $F^{0}$ oxygen flux across the SWI, $\varphi$ sediment porosity, $D_{s}$ diffusion coefficient in sediment pore water

$z=\frac{\operatorname{In}\left(\frac{c_{0}}{c_{\mathrm{h}}}\right)}{\sqrt{K}}=\delta$

For zero-order reaction kinetics, we substituted $c=c_{\mathrm{h}}$ into Eq. (9), giving a solution of

$z=\frac{\sqrt{2 K c_{0}} \pm \sqrt{2 K c_{\mathrm{h}}}}{K}$

According to Fig. 2, the larger solution of Eq. (11) should be rejected, giving a final solution of

$z=\frac{\sqrt{2 K c_{0}}-\sqrt{2 K c_{\mathrm{h}}}}{K}=\delta$

when $c_{\mathrm{h}}=0.2 \mathrm{mg} / \mathrm{L}$ (Higashino 2011) and the simulated $\mathrm{K}$ and $c_{0}$ were substituted into Eqs. (10) and (12) to obtain penetration depths $\delta$ for these two conditions.

\section{Calculation of oxygen flux through the oxygen profile}

Fick's First Law was used to calculate the oxygen flux across the SWI (Sweerts et al. 1991; House 2003). It was expressed as follows:

$\mathrm{F}^{0}=\varphi \times D \mathrm{~s} \times \frac{\mathrm{d} c}{\mathrm{~d} z}(z=0)$ 
We can measure the porosity $(\varphi)$ or obtain its value by referring to other studies. The diffusion coefficient in sediment pore water $\left(D_{\mathrm{s}}\right)$ can be derived from the following equation (House 2003)

$\operatorname{Ds}=\operatorname{Dm}\left(1-\operatorname{In} \varphi^{2}\right)$

where $D_{\mathrm{m}}$ is the molecular diffusion coefficient in water. The DO gradient in the SWI $\frac{\mathrm{d} c}{\mathrm{~d} z}(z=0)$ can be obtained by first derivation of the oxygen profile equation. We will discuss this for zero- and first-order reaction kinetics respectively.

In the case of a first-order reaction, using a derivative with respect to $z$ in Eq. (5), the DO gradient in the SWI can be expressed as

$\frac{\mathrm{d} c}{\mathrm{~d} z}(z=0) \sqrt{2 \times K \times c_{0}}$

Substituting Eqs. (14) and (15) into Eq. (13) gives the following result for the final sediment oxygen flux:

$\mathrm{F}^{0}=\varphi \times \sqrt{2 \times \mathrm{K} \times c_{0}} \times D_{\mathrm{m}}\left(1-\operatorname{In} \varphi^{2}\right)$

In the case of the zero-order reaction, a similar procedure is carried out for Eq. (9), and the DO gradient in the SWI becomes:

$\frac{\mathrm{d} c}{\mathrm{~d} z}(z=0)=c_{0} \sqrt{K}$

Substituting Eqs. (14) and (17) into Eq. (13) gives the final sediment oxygen flux:

$\mathrm{F}^{0}=-\varphi \times c_{0} \times \sqrt{K} \times D_{\mathrm{m}}\left(1-\operatorname{In} \varphi^{2}\right)$

Sediment preparation and sediment porosity measurements

Four surface sediment samples, collected from the Ziya River, Hebei Province, China, were used in this study. The physiochemical properties are listed in Table 1. The organic matter contents were especially high for sediment 1 and sediment 2 . The water content of the four sediment samples ranged from 64.18$70.55 \%$, and variation in the particle size (mean volume diameter) and specific surface area between the samples is shown in Table 1. The river water in sediment sample 4 was red during collection, which was due to an iron-rich wastewater discharge.
Table 1 shows that $\mathrm{Fe}$ and $\mathrm{Mn}$ concentrations in sediment 4 were much higher than in other sediments.

The sediment samples were maintained at $4{ }^{\circ} \mathrm{C}$ during transport to the laboratory. Before analysis, about 70 -g sediment was mixed with $200-\mathrm{ml}$ deionized water in a $400-\mathrm{ml}$ beaker. The plant residues and detritus in sediment were removed to prevent damage to the microelectrode during the oxygen profile measuring. The suspended sediment settled quickly and was incubated in the dark at $25{ }^{\circ} \mathrm{C}$ for about 2 days. After the incubation, a distinct, stable sediment-water interface that was suitable for the oxygen profile measuring had formed.

The sediment porosity of each sample was measured when the oxygen profiling was finished. It was calculated using the following formula (Berner 1980)

$\varphi=\frac{V_{\mathrm{pw}}}{V_{\mathrm{b}}}$

where $V_{\mathrm{pw}}$ was the volume of pore water and $V_{\mathrm{b}}$ was the bulk volume of the sediment. The specific experiment procedures were as follows: First, the SWI and the top of the overlying water were marked on the beaker (These marks are used later to determine the volume of bulk sediment and overlying water.). The beaker was weighed and the mass $M_{1}$ was recorded. The beaker was then placed into a drying oven at a temperature of $105^{\circ} \mathrm{C}$ until the water had dried up. The beaker was reweighed and the mass $M_{2}$ was recorded. Finally, the beaker was washed and water was added up to the marks. The volume of the added water between the two marks was measured and recorded as $V_{1}$ and $V_{2} . V_{1}$ is equal to $V_{\mathrm{b}}$, and volume of pore water was calculated as follows:

$V_{\mathrm{pw}}=\frac{M_{\mathrm{pw}}}{\rho_{\mathrm{w}}}=\frac{\left(M_{1}-M_{2}-V_{2} \times \rho_{\mathrm{w}}\right)}{\rho_{\mathrm{w}}}$

where $M_{\mathrm{pw}}$ was the mass of pore water and $\rho_{\mathrm{w}}$ was density of water and was equal to 1 . The porosity was calculated by substituting Eq. (20) into Eq. (19) as follows:

$\varphi=\frac{\left(M_{1}-M_{2}-V_{2} \times \rho_{\mathrm{w}}\right)}{V_{1} \times \rho_{\mathrm{w}}}$

\section{Results and discussion}

DO microprofiles and the reaction kinetics

The DO microprofiles of the four prepared sediments are shown in Fig. 3. Oxygen was rapidly exhausted and concentrations approached zero several millimeters into the sediment. Generally, the oxygen concentration will decrease 
Table 1 The physiochemical properties of sediment samples

\begin{tabular}{lllllll}
\hline $\begin{array}{l}\text { Sample } \\
\text { number }\end{array}$ & $\begin{array}{l}\text { Content of organic } \\
\text { matter }^{\mathrm{a}}(\%)\end{array}$ & $\begin{array}{l}\text { Content of } \mathrm{Fe}^{\mathrm{b}} \\
(\mathrm{mg} / \mathrm{g})\end{array}$ & $\begin{array}{l}\text { Content of } \mathrm{Mn}^{\mathrm{b}} \\
(\mathrm{mg} / \mathrm{g})\end{array}$ & $\begin{array}{l}\text { Content of water } \\
(\%)\end{array}$ & $\begin{array}{l}\text { Mean volume diameter } \\
(\mu \mathrm{m})\end{array}$ & $\begin{array}{l}\text { Specific surface area }^{\mathrm{c}} \\
\left(\mathrm{m}^{2} / \mathrm{g}\right)\end{array}$ \\
\hline 1 & 23.64 & 30.85 & 0.34 & 69.23 & 42.81 & 0.424 \\
2 & 29.13 & 18.02 & 0.25 & 72.74 & 98.77 & 0.291 \\
3 & 4.46 & 3.63 & 0.03 & 64.18 & 68.93 & 0.351 \\
4 & 8.85 & 156.42 & 0.96 & 70.55 & 37.66 & 0.399 \\
\hline
\end{tabular}

${ }^{\mathrm{a}}$ Measured by loss on ignition

${ }^{\mathrm{b}}$ Measured by inductively coupled plasma optical emission spectrometer (ICP-OES)

${ }^{\mathrm{c}}$ Measured by Malvern laser particle size analyzer

immediately below the SWI. DO declines in the pore water mainly through biological catalytic processes, such as organic carbon consumption by benthic organisms or aerobic bacteria, and by biologically mediated oxidation of reduced inorganic species (Santschi et al. 1990). The observed DO changed smoothly although there was some variation between the first and last few data points. However, in real sediments, larger variation may be expected in the DO microprofile because the sediment structure is heterogeneous. In some cases, the oxygen levels may even show peaks below the SWI as a result of the burrowing effect of macroinvertebrates (Hebert et al. 2007). In our study, the prepared sediment was homogeneous and no macroinvertebrates existed, so there were no large fluctuations in the DO microprofiles. The vertical DO profile in the sediment pore water indicated that the microelectrode was reliable.

We can see from Table 2 that the $R^{2}$ for the zero-order reaction was higher than for the first-order reaction for all the sediments. The zero-order reaction model, therefore, was more suitable for the sediments, and the microorganisms were the main factors controlling the kinetics of DO consumption in sediments. The following equation (Rabouille and Gaillard 1991) describes the relationship between the DO consumption rate and the $\mathrm{DO}$ concentration:

$R_{0_{2}}=k \times \frac{\left[0_{2}\right]}{\left[0_{2}\right]+K_{\mathrm{O} 2}}$

where $k$ is the rate constant, $\left[\mathrm{O}_{2}\right]$ is the $\mathrm{DO}$ concentration, and $K_{\mathrm{O} 2}$ is the half saturation constant. This means that when DO is much larger than $K_{\mathrm{O} 2}, R_{\mathrm{O} 2}$ will be independent of DO. Also, if DO is smaller than $K_{\mathrm{O} 2}, R_{\mathrm{O} 2}$ will be dependent on the DO concentration. Heterotrophic bacteria reach half their maximum growth rates when oxygen concentrations are $0.1 \mathrm{mg} / \mathrm{L}$, whereas nitrifying bacteria reach half their maximum growth rates at concentrations between 0.5 and $4.0 \mathrm{mg} / \mathrm{L}$ (Stenstrom and Poduska 1980). In this study, organic matter content in
Fig. 3 Measured DO microprofiles and the simulation results in four prepared sediments. Ost represents zeroorder kinetics model and 1st represents first-order kinetics model

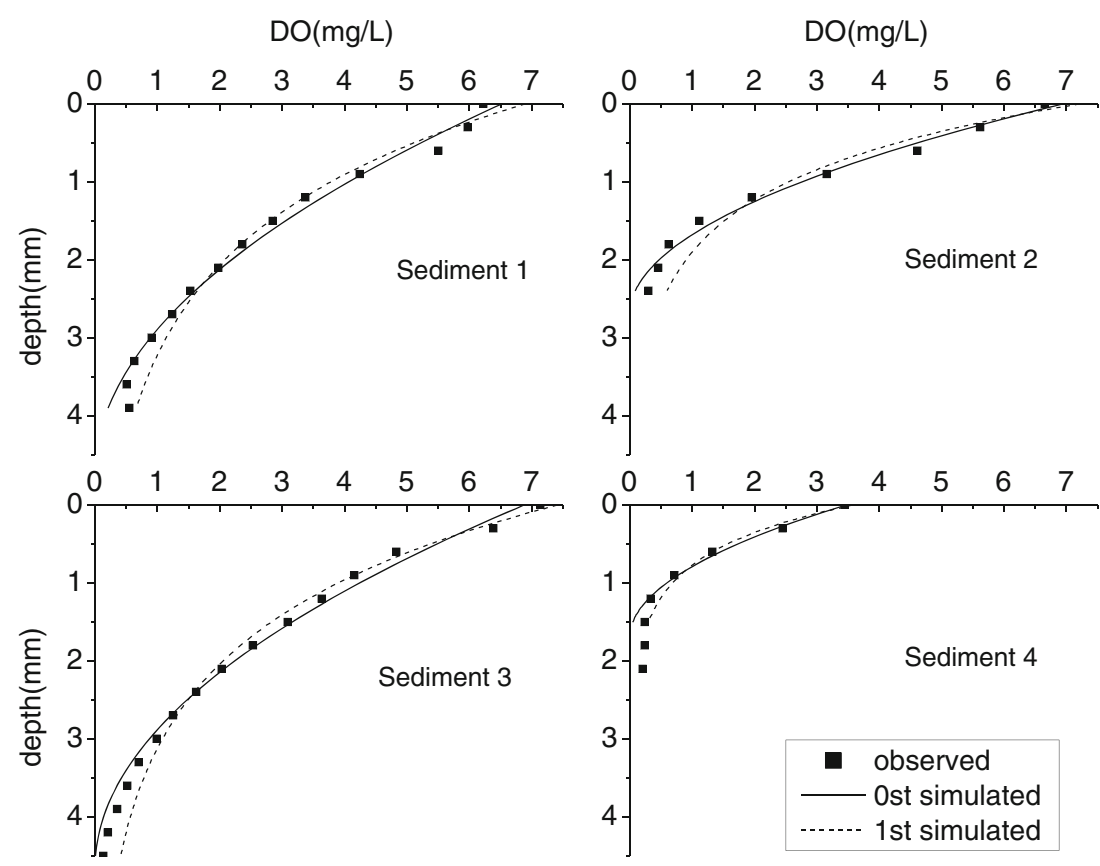


Table 2 Parameters estimation in oxygen profile simulation

\begin{tabular}{|c|c|c|c|c|c|c|}
\hline \multirow[t]{2}{*}{ Sediment number } & \multicolumn{3}{|c|}{ Zero order } & \multicolumn{3}{|c|}{ First order } \\
\hline & $K=k / D_{\mathrm{s}}$ & $c_{0}$ & $R^{2}$ & $K=k / D_{\mathrm{s}}$ & $c_{0}$ & $R^{2}$ \\
\hline 1 & 0.578 & 6.520 & 0.986 & 0.361 & 6.897 & 0.974 \\
\hline 2 & 1.899 & 6.939 & 0.989 & 1.080 & 7.201 & 0.958 \\
\hline 3 & 0.635 & 6.876 & 0.991 & 0.412 & 7.408 & 0.990 \\
\hline 4 & 2.384 & 3.463 & 0.990 & 2.732 & 3.574 & 0.981 \\
\hline
\end{tabular}

sediment was high, indicating that heterotrophic bacteria dominated the oxygen consumption. Zero-order kinetics are therefore appropriate when the oxygen content is greater than $0.1 \mathrm{mg} / \mathrm{L}$, which agrees with our results. In summary, the kinetic models developed in this method were appropriate and provided good oxygen profile simulations.

Oxygen reaction rate and DO concentrations at the sedimentwater interface

Table 2 shows that the simulated reaction rate constants varied between the sediments. In particular, sediment 2 and sediment 4 had higher oxygen consumption rate constants than sediment 1 and sediment 3 , regardless of whether the zero- or firstorder kinetics model was applied. The simulated rate constant is the overall expression of different sources of oxygen consumption, such as organic matter decomposition, nitrification, and oxidation of reduced substances. Although these sources can be simulated individually by complicated reaction models (Cai et al. 2010), the overall rate is still valuable because it is useful for calculating sediment oxygen demand. There was no relationship between sediment organic matter content and the simulated rate constant, which may be attributable to the different decomposable organic matter contents in these sediments, which corresponds to oxygen consumption rate constant actually (Westrich and Berner 1984).

DO concentrations in the interface, or in the SWI, depend on the extent of oxygen depletion of the overlying water. Table 2 shows that the interface DO concentration of sediment 4 was much lower than for the other three sediments. Given that the sediment was mixed with deionized water that would not deplete any oxygen, the large degree of oxygen depletion in the overlying water of sediment 4 must have been caused by the release of reduced substances from the sediment. This is similar to hypolimnetic hypoxia that has been observed in other studies (Beutel 2003; Edwards et al. 2005; Gantzer et al. 2009). Overall, the interface oxygen concentration and the oxygen reaction rate provided information that was useful in the sediment oxygen analysis.

\section{DO penetration and oxygen flux across SWI}

We calculated the penetration depth and oxygen flux across the SWI based on the zero-order kinetics model because it produced a higher $R^{2}$ than the first-order model in the simulation. The oxygen penetration depth of the four sediments ranged from 1.29 to $3.92 \mathrm{~mm}$ (Table 3) and was greatest for sediment 1 and least for sediment 4. Equation (12) was used to calculate the penetration depth, by assigning $c_{\mathrm{h}}$ as $0.20 \mathrm{mg} / \mathrm{L}$, under which the growth of most aerobic heterotrophic bacteria is restricted. In fact, the value of $c_{\mathrm{h}}$ can be changed depending on the purpose. For instance, we can identify the best nitrifying zone in the sediment by assigning a value of $0.50 \mathrm{mg} / \mathrm{L}$ to $c_{\mathrm{h}}$, the concentration at which half saturated growth rates of nitrifying bacteria occur (Stenstrom and Poduska 1980). Compared with results when $c_{\mathrm{h}}=0.20 \mathrm{mg} / \mathrm{L}$ and when $c_{\mathrm{h}}=0.50 \mathrm{mg} /$ $\mathrm{L}$, the penetration depths of the four sediments decreased to between 1.06 and $3.40 \mathrm{~mm}$. It is of note that the two models differ when the equations are used to calculate the penetration depth. For zero-order reactions (Eq. (12)), the maximum penetration depth is a function of $c_{0}$ when $c_{\mathrm{h}}=0$. However, for first-order reactions (Eq. (10)), the penetration depth can be infinitely greater when $c_{\mathrm{h}}$ approaches zero. Therefore, if the first-order model is used, it is better to assign a value greater than zero to $c_{\mathrm{h}}$.

Results of porosity, DO gradient and oxygen flux calculation are presented in Table 3. Porosity ranged from 0.7 to 0.9 and showed little variation. Sediment 2 and sediment 4 had larger oxygen gradients than sediment 1 and sediment 3 . Oxygen fluxes ranged from 0.061 to $0.114 \mathrm{mg} / \mathrm{cm}^{2} / \mathrm{day}$, which is comparable with other studies (Sweerts et al. 1991; Bryant et al. 2010). According to Eq. (13), the oxygen flux results are influenced by three factors: porosity, the interface
Table 3 Calculation of penetration depth and oxygen flux based on zero-order reaction kinetics

\begin{tabular}{lllll}
\hline Samples & Sediment 1 & Sediment 2 & Sediment 3 & Sediment 4 \\
\hline$K\left(\mathrm{mg} / \mathrm{L} / \mathrm{mm}^{2}\right)$ & 0.58 & 1.90 & 0.63 & 2.38 \\
$c_{0}(\mathrm{mg} / \mathrm{L})$ & 6.52 & 6.94 & 6.88 & 3.46 \\
Penetration depth $(\mathrm{mm})$ & 3.92 & 2.24 & 3.86 & 1.29 \\
Porosity & 0.87 & 0.86 & 0.71 & 0.80 \\
Interface DO gradient $(\mathrm{mg} / \mathrm{L} / \mathrm{mm})$ & 2.75 & 5.13 & 2.96 & 4.06 \\
$D_{\mathrm{m}}\left(\mathrm{cm}^{2} /\right.$ day $)$ & 1.98 & 1.98 & 1.98 & 1.98 \\
Oxygen flux $\left(\mathrm{mg} / \mathrm{cm}^{2} /\right.$ day) & 0.061 & 0.114 & 0.070 & 0.093 \\
\hline
\end{tabular}


oxygen gradient, and the diffusive coefficient in sediment. Given that the diffusive coefficient in sediment is calculated from porosity (Eq. (15)), the oxygen flux calculation is actually controlled by the first two factors. First, we measured the porosity of the bulk sediment, which may result in underestimation of the surface layer porosity due to sediment compaction (Berner 1980). This uncertainty can be avoided by using the porosity of the top layer when analyzing sediment samples extracted by coring. Second, the oxygen gradient was calculated based on the simulated $K$ and $c_{0}$ (Eq. (14)). If the sediment surface is highly heterogeneous, there may be great variation between the simulated parameters for different places. The sediment used in this study displayed good homogeneity, so the variation in DO microprofiles for different parts of the sediment was expected to be small. However, when using sediment samples extracted by coring, the DO microprofile should be analyzed as many times as possible to reduce simulation errors.

\section{Conclusion}

We constructed a sediment oxygen analysis system based on an oxygen microelectrode and a control device. Methods were developed to simulate the DO microprofile and to calculate the sediment oxygen consumption rate, oxygen penetration depth, and the oxygen flux across the SWI. The microelectrode successfully displayed the microprofiles of DO in the prepared sediments. The fit of the modeled to the observed data indicated that the kinetic models used in our methods were reasonable. However, the zero-order kinetics model was a better fit for our sediment samples than the first-order model because it produced a higher $R^{2}$. In our study, the oxygen penetration was determined by assigning a value to $c_{\mathrm{h}}$, and the oxygen flux was dependent on porosity and the interface oxygen gradient. The calculated penetration depths and oxygen fluxes ranged from 1.29 to $3.92 \mathrm{~mm}$ to 0.061 to $0.114 \mathrm{mg} /$ $\mathrm{cm}^{2} /$ day, respectively. These values are comparable with those observed for other studies. Overall, the sample measurement and model calculation results indicated that this is a reliable method for sediment oxygen analysis.

Acknowledgments This work was supported by the Research \& Development on Suitable Key Technologies of the Village Environmental Monitoring (no. 2012BAJ24B01).

\section{References}

Alabaster JS, Lloyd R (1982) Water quality criteria for fresh water fish. Butterworth Scientific, London

Berner RA (1980) Early diagenesis: a theoretical approach, vol 1. Princeton University, Princeton
Beutel MW (2001) Oxygen consumption and ammonia accumulation in the hypolimnion of Walker Lake, Nevada. Hydrobiologia 466(1-3): 107-117

Beutel MW (2003) Hypolimnetic anoxia and sediment oxygen demand in California drinking water reservoirs. Lake Reserv Manag 19(3): 208-221

Bouldin DR (1968) Models for describing the diffusion of oxygen and other mobile constituents across the mud-water interface. J Ecol 56(1):77-87

Bowman GT, Delfino JJ (1980) Sediment oxygen-demand techniques - a review and comparison of laboratory and in situ systems. Water Res 14(5):491-499

Brady DC, Testa JM, Di Toro DM, Boynton WR, Kemp WM (2013) Sediment flux modeling: calibration and application for coastal systems. Estuar Coast Shelf Sci 117:107-124

Brafield A (1964) The oxygen content of interstitial water in sandy shores. J Anim Ecol 33(1):97-116

Brendel PJ, Luther GWIII (1995) Development of a gold amalgam voltammetric microelectrode for the determination of dissolved $\mathrm{Fe}$, $\mathrm{Mn}, \mathrm{O}_{2}$, and $\mathrm{S}$ (-II) in porewaters of marine and freshwater sediments. Environ Sci Technol 29(3):751-761

Bryant LD, McGinnis DF, Lorrai C, Brand A, Little JC, Wüest A (2010) Evaluating oxygen fluxes using microprofiles from both sides of the sediment-water interface. Limnol Oceanogr-Meth 8:610-627

Cai W-J, Sayles FL (1996) Oxygen penetration depths and fluxes in marine sediments. Mar Chem 52(2):123-131

Cai WJ, Luther GW, Cornwell JC, Giblin AE (2010) Carbon cycling and the coupling between proton and electron transfer reactions in aquatic sediments in Lake Champlain. Aquat Geochem 16(3):421446

Di Toro DM, Connolly JP (1980) Mathematical models of water quality in large Lakes Part 2: Lake Erie. USEPA report: EPA-600/3-80-065

Edwards WJ, Conroy JD, Culver DA (2005) Hypolimnetic oxygen depletion dynamics in the central basin of Lake Erie. J Great Lakes Res 31(S2):262-271

Gantzer PA, Bryant LD, Little JC (2009) Effect of hypolimnetic oxygenation on oxygen depletion rates in two water-supply reservoirs. Water Res 43(6): 1700-1710

Hanes N, Irvine RL (1966) Oxygen uptake rates of benthal systems by a new technique. Proceedings of the 21 st Industrial Waste Conference

Hargrad BT (1972) Aerobic decomposition of sediment and detritus as a function of particle surface area and organic content. Limnol Oceanogr 17(4):583-597

Hebert AB, Morse JW, Eldridge PM (2007) Small-scale heterogeneity in the geochemistry of seagrass vegetated and nonvegetated estuarine sediments: causes and consequences. Aquat Geochem 13(1):19-39

Henriksen K (1980) Measurement of in situ rates of nitrification in sediment. Microb Ecol 6(4):329-337

Higashino M (2011) Oxygen consumption by a sediment bed for stagnant water: comparison to SOD with fluid flow. Water Res 45(15):43814389

Holmer M (1999) The effect of oxygen depletion on anaerobic organic matter degradation in marine sediments. Estuar Coast Shelf Sci 48(3):383-390

House WA (2003) Factors influencing the extent and development of the oxic zone in sediments. Biogeochemistry 63(3):317-334

Jorgensen BB, Revsbech NP (1985) Diffusive boundary layers and the oxygen uptake of sediments and detritus. Limnol Oceanogr 30(1): $111-122$

Kemp W, Sampou P, Caffrey J, Mayer M, Henriksen K, Boynton W (1990) Ammonium recycling versus denitrification in Chesapeake Bay sediments. Limnol Oceanogr 35(7):1545-1563

Louati H, Said OB, Got P, Soltani A, Mahmoudi E, Cravo-Laureau C, Duran R, Aissa P, Pringault O (2013) Microbial community responses to bioremediation treatments for the mitigation of low- 
dose anthracene in marine coastal sediments of Bizerte lagoon (Tunisia). Environ Sci Pollut Res 20(1):300-310

Luther GW III, Glazer BT, Ma S, Trouwborst RE, Moore TS, Metzger E, Kraiya C, Waite TJ, Druschel G, Sundby B (2008) Use of voltammetric solid-state (micro) electrodes for studying biogeochemical processes: laboratory measurements to real time measurements with an in situ electrochemical analyzer (ISEA). Mar Chem 108(3-4):221-235

Martin N, McEachern P, Yu T, Zhu DZ (2013) Model development for prediction and mitigation of dissolved oxygen sags in the Athabasca River, Canada. Sci Total Environ 443:403-412

Meysman FJ, Galaktionov O, Glud RN, Middelburg JJ (2010) Oxygen penetration around burrows and roots in aquatic sediments. J Mar Res 68(2):309-336

Rabouille C, Gaillard JF (1991) A coupled model representing the deepsea organic carbon mineralization and oxygen consumption in surficial sediments. J Geophys Res 96(C2):2761-2776

Revsbech NP, Jorgensen BB, Blackburn TH, Cohen Y (1983) Microelectrode studies of the photosynthesis and $\mathrm{O}_{2}, \mathrm{H}_{2} \mathrm{~S}$, and $\mathrm{pH}$ profiles of a microbial Mat. Limnol Oceanogr 28(6):1062-1074

Santschi P, Höhener P, Benoit G, Buchholtz-ten Brink M (1990) Chemical processes at the sediment-water interface. Mar Chem 30: 269-315

Stenstrom MK, Poduska RA (1980) The effect of dissolved oxygen concentration on nitrification. Water Res 14(6):643-649

Sundby B, Anderson LG, Hall POJ, Iverfeldt $\AA$, van der Loeff MMR, Westerlund SFG (1986) The effect of oxygen on release and uptake of cobalt, manganese, iron and phosphate at the sediment-water interface. Geochim Cosmochim Ac 50(6):1281-1288

Sweerts JPRA, Bar-Gilissen MJ, Cornelese AA, Cappenberg TE (1991) Oxygen-consuming processes at the profundal and littoral sediment-water interface of a small meso-eutrophic lake (Lake Vechten, The Netherlands). Limnol Oceanogr 36(6):1124-1133

Torres E, Ayora C, Canovas CR, Garcia-Robledo E, Galvan L, Sarmiento AM (2013) Metal cycling during sediment early diagenesis in a water reservoir affected by acid mine drainage. Sci Total Environ 461:416-429

Wang W (1980) Fractionation of sediment oxygen demand. Water Res 14(6):603-612

Wang W (1981) Kinetics of sediment oxygen demand. Water Res 15(4): 475-482

Westrich JT, Berner RA (1984) The role of sedimentary organic matter in bacterial sulfate reduction: the $\mathrm{G}$ model tested. Limnol Oceanogr 29(2):236-249

Wetzel RG (2001) Limnology: lake and river ecosystems. Academic, San Diego

Xu KM, Zhang LP, Zou WB (2009) Microelectrode study of oxygen uptake and organic matter decomposition in the sediments of Xiamen Western Bay. Estuar Coast 32(3): 425-435

Zahraeifard V, Deng ZQ (2012) Modeling sediment resuspensioninduced DO variation in fine-grained streams. Sci Total Environ 441:176-181 